\title{
La cueva de Gorham en Gibraltar. La supervivencia tardía de los neanderthales en el extremo más meridional de Europa
}

El peñón de Gibraltar es una península orientada de norte a sur de $6 \mathrm{~km}$ de superficie, 5,2 de longitud y $1,6 \mathrm{~km}$ de anchura. Tiene un relieve muy abrupto con grandes paleo-acantilados verticales en la ladera oriental y un pie de monte con un bosque mediterráneo templado en la parte occidental. El peñón está rodeado por el mar Mediterráneo a excepción de un istmo de arena de dunas al norte que lo une con la Peninsula lbérica.

Históricamente, ya desde mediados del siglo XVIII, Gibraltar ha sido un lugar importante en hallazgos paleontológicos como la brecha ósea del Rosia Bay, descrita por John Boddington en 1870. En cuanto a descubrimientos paleontológicos humanos, cabe citar el descubrimiento del cráneo de un neandertal adulto en la cantera de Forbes (1848) y un fragmento de cráneo de un niño neandertal en el abrigo de Delvi's Tower en 1928.

El nombre de la cueva se debe al capitán A. Gorham, que la descubrió en 1907, aunque su importancia como yacimiento arqueológico no se dio a conocer hasta los años 40 por los miembros de la Royal Electrical Ingenier. John d'Arcy Waechter, miembro del Instituto Británico de Arqueología en Ankara, a propuesta de Ms. Garrod, realizó varias campañas de excavaciones entre 1948 y 1954 en la zona externa de la cavidad.

En 1991 se reanudaron las excavaciones por un equipo de investigación bajo la dirección de Clive Finlayson (Museo de Gibraltar) y la colaboración del Museo de Historia Natural de Londres. En 1994 se constituye el Gibraltar Cave Project bajo el liderazgo de Finlayson, con la colaboración de C. Striger (museo de Historia Natural), N. R. Barton (Universidad de Oxford), Francisco Giles Pacheco (museo Arqueológico del Puerto de Santa María), J. Rodríguez Vidal (Universidad de Huelva), Darren Fa y G. Finlayson (Gibraltar Museum).

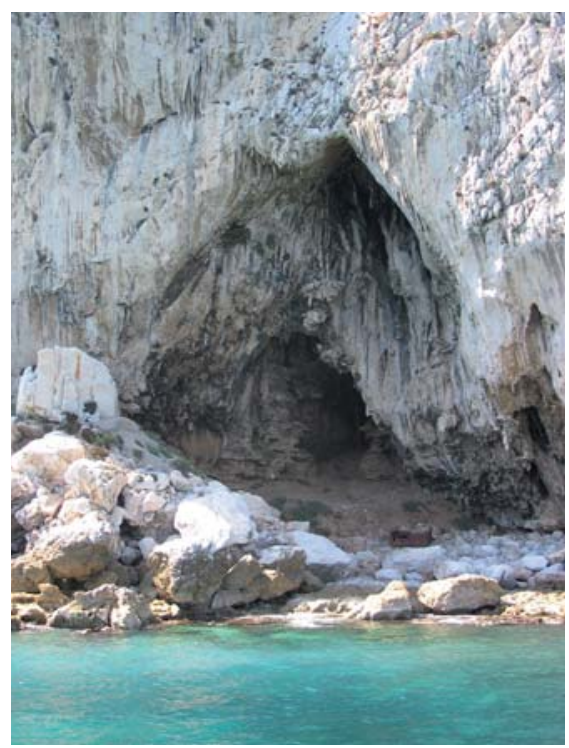

La cueva de Gorham a pie del acantilado; entrada de 30 metros de altura. Foto: Francisco Giles
El objetivo especifico fue establecer las caracteristicas paleo-ecológicas de las poblaciones de neandertales hasta su extinción, ampliándose las excavaciones en la zona del interior de la cavidad con la intención de abarcar el Holoceno y Pleistoceno superior.

\section{Secuencia arqueológica}

En el estado actual de las investigaciones, se han podido individualizar cinco niveles arqueológicos que desvelan la presencia de poblaciones en la cueva desde épocas prerromanas hasta ocupaciones más modernas de grupos de neandertales que hasta la fecha se conocen en toda Europa.

El registro arqueológico nos permite establecer que entre finales del siglo IX y mediados del siglo II a. d. C. la cueva de Gorham se convirtió en un lugar de referencia a escala mediterránea. La posición de la cavidad, abierta al mar Mediterráneo y paso obligatorio de los navegantes orientales hacia el extremo de Occidente, dotó a este espacio geográfico de una gran carga simbólica y mitológica, configurando a esta cueva y las columnas de Melkart-Herakles como espacio ignoto del confin, un verdadero finis terrae para las civilizaciones mediterráneas de la época. La prueba del trasiego de gente, mercancias e ideas que surcaron este mar durante siete siglos lo atestigua una gran variedad de objetos cerámicos y ornamentos personales encontrada en la superficie (nivel I) de la cavidad. Tales objetos constituyen testimonio de las ofrendas consagradas a los dioses tutelares del santuario, protectores de la navegación en las singladuras comerciales entre Oriente y Occidente. Están representadas la fase arcaica, clásica y helenistica de la Antigüedad, permitiendo discriminar la presencia de productos cananeos egipcios, fenicio-occidentales y tartésicos, griegos, ibero- itálicos.

Todo parece indicar que durante la Prehistoria reciente (IV-V milenio a.n.e.) la cueva de Gorham formó parte de una serie de lugares que eran frecuentados por los primeros productores neolíticos. En el interior de la cavidad se han hallado ajuares de cerámicas y herramientas líticas y utillajes vinculados a gran cantidad de productos malacológicos y mamíferos marinos (foca monje), datados por $\mathrm{C} 14$ en el $\mathrm{V}$ milenio a. de $\mathrm{C}$. y que dan testimonio del aprovechamiento de los recursos del mar en épocas estacionales del año astronómico.

Santuario de arte rupestre, el nivel III de la cueva de Gorham delata la presencia de Homo sapiens sapiens (hominidos anatómicamente modernos), con una tecnología asociada al Paleolítico superior, que engloba una ocupación de época solutrense y registros de industria magdaleniense. Las industrias lítica y ósea se adscriben en un contexto cronoestratigráfico estacional, manteniendo hogares y suelos de ocupación con fauna consumida. El conjunto tecno-cultural está relacionado con puntas de flechas bifaciales, punzones y azagayas de hueso características de paleopoblaciones de cazadores recolectores solutrenses, así como manifestaciones de arte parietal con grabados y pinturas con representaciones de caballos, bóvidos, cáprinos, cérvidos, y negativos de manos humanas. Estos conjuntos de arte parietal y mueble tipifican a la cueva de Gorham como un santuario de arte rupestre y lugar de asociación espiritual y simbólica entre las poblaciones del Solutrense ibérico en la región del Estrecho de Gibraltar, cuya cronología absoluta en $\mathrm{C} 14$ abarca desde el 16.420 al $18.440 \mathrm{BP}$ y $20.000 \mathrm{ka}$ BP. Es en el nivel IV, adscrito tecno-culturalmente a Musteriense (Paleolítico medio), en el que se ha constatado la supervivencia tardia de poblaciones de homínidos neandertales, datos basados en un registro de alta resolución de ocupación de la gruta de Gorham, que establece la supervivencia hasta hace 24.010-26.070 ka BP.

Esta población de neandertales sobrevivió en el punto más meridional de Europa, dentro de un contexto fisiográfico privilegiado, siendo las últimas poblaciones registradas hasta la fecha actual. Estos resultados demuestran que los neandertales sobrevivieron aislados hasta bien entrada la llegada de los humanos modernos a Europa. Tales dataciones sugieren que la cueva fue un lugar escogido y visitado asiduamente durante varios miles de años. Su situación y morfología permiten la realización de hogares en el interior de la cavidad y la entrada de luz natural hasta bastante profundidad. Las fechas tardias se obtuvieron in situ con una serie de muestras de carbones en las hogueras musterienses. Dichas dataciones proporcionan unas cronologias entre $24.010+/-322$ hasta 28.000 BP en un contexto técnico -cultural del Musteriense tardio -

Los últimos neandertales que ocuparon la cueva de Gorham tuvieron acceso a una variada comunidad de flora y vertebrados continentales y marinos entre la Ilanura arenosa, zona de bosques, lagunas costeras y acantilados rocosos. Este medio ecológico tan diverso pudo haber facilitado la larga pervivencia. El patrón general de fauna y vegetación detectado en las excavaciones de la cueva, nivel IV Musteriense tardio, es consistente con el exterior de la cueva durante la mayor parte del Pleistoceno superior y revela condiciones de refugio glacial del Mediterráneo con un clima termo-mediterráneo sub-húmedo durante el Pleistoceno superior en el sur de la Península Ibérica.

Francisco Giles Pacheco

Codirector del Gibraltar Cave Project

\section{Bibliografía}

FINLAYSON, C. (2010) El sueño del neandertal. Barcelona: Critica, 2010

FINLAYSON, C.; GILES PACHECO, F.; RODRÍGUEZ

VIDAL, J. et ál. (2006) Late survival of Neanderthals at the southernmost extreme of Europe. Nature, n. ${ }^{\circ} 443,2006$, pp. 850-853

GUTIÉRREZ LÓPEZ, J. M.; REINOSO DEL RÍO, M. C.; GILES PACHECO, F. et ál. (2001) Gorham: Una cueva santuario durante la antigüedad. Boletin de la Sociedad Española de Espeleologia y Ciencias del Karst (Sedeck), n. 2, 2001

Agradecimientos: Gibraltar Museum, Government of Gibraltar 